Confirmation of this idea has been forthcoming in the analysis of the electronic spectra of several partly deuterated benzenes. In $1: 3: 5-\mathrm{C}_{6} \mathrm{H}_{3} \mathrm{D}_{3}$, the excited state frequencies, $3138 \mathrm{~cm} .^{-1}$ and 2337 cm. ${ }^{-1}$, can be assigned to $A_{1}^{\prime}(H)$ and $A_{1}^{\prime}(D)$ vibrations respectively. The corresponding values for the ground-state are $3053 \mathrm{~cm}^{-1}$ and $2282 \mathrm{~cm}^{-1}{ }^{4}$. Perhaps the strongest argument is that, in the absorption spectrum of $1: 4-\mathrm{C}_{8} \mathrm{H}_{8} \mathrm{D}_{2}$, the progression corresponding to the $\mathrm{C}_{8} \mathrm{H}$ progression $0-0+3085+923 v_{1}$ is doubled, while that correspond ing to the $\mathrm{C}_{6} \mathrm{D}_{6}$ progression $0-0+2320+879 v_{1}^{\prime}$ remains single is single and the latter double. In $\mathrm{C}_{6} \mathrm{H}_{6}$ and $\mathrm{C}_{6} \mathrm{D}_{6}$, Sponer assigned the frequencies 3085 and $2320 \mathrm{~cm}^{-1}$ to a combination of an $E_{g}^{+}(\mathrm{C})$ and an $A_{1} g(\mathrm{H})$ vibration, whereas we have assigned them to a fundamental $E_{\sigma}^{+}(\mathrm{H})$ vibration. For $\mathrm{C}_{8} \mathrm{H}_{6} \mathrm{D}_{2}$ and $\mathrm{C}_{6} \mathrm{H}_{2} \mathrm{D}$, the distinction follows that, whereas Sponer's view would permit only the two $A$ g hydrogenstretching vibrations to start progressions, our analysis additionally allows the related $B_{1} g$ vibration to give the extra progression which in
each case is observed. A summary of the ground- and excited-state frequencies (in $\mathrm{cm}^{-1}$ ) of the $A_{1 \sigma^{-}}, B_{1} u^{-}$and $E_{\sigma^{-}}^{+}$like hydrogen-stretching vibrations of some isotopic benzenes is given below.

\begin{tabular}{|c|c|c|c|c|c|c|c|c|}
\hline \multirow{2}{*}{ State } & \multicolumn{3}{|c|}{$D_{6} h$} & \multicolumn{2}{|c|}{$D_{9} h$} & \multicolumn{3}{|c|}{$\mathrm{V}_{\boldsymbol{h}}$} \\
\hline & Sym. & $\mathrm{C}_{6} \mathrm{H}_{8}$ & $\overrightarrow{\mathrm{C}_{6} \mathrm{D}_{6}}$ & Sym. & $\mathrm{C}_{6} \mathrm{H}_{3} \mathrm{D}_{3}$ & \multirow[t]{3}{*}{ Sym. } & \multirow{3}{*}{$\mathrm{C}_{8} \mathrm{H}_{4} \mathrm{D}_{2}$} & \multirow[t]{3}{*}{$\mathrm{C}_{6} \mathrm{H}_{2} \mathrm{D}_{4}$} \\
\hline Ground & & 3060 & 2290 & \multirow{4}{*}{$A_{1}^{\prime}$} & 2282 & & & \\
\hline Excited & $\boldsymbol{D}_{1} \mathrm{z}$ & 3138 & 2337 & & 2337 & & & \\
\hline Ground & \multirow{2}{*}{$A_{1} g$} & 3062 & 2293 & & 3053 & \multirow{3}{*}{$A_{\boldsymbol{g}}$} & 2280 & 3045 \\
\hline Excited & & 3130 & 2361 & & 3138 & & 2353 & 3132 \\
\hline $\begin{array}{l}\text { Ground } \\
\text { Excited }\end{array}$ & \multirow{2}{*}{$\dot{E_{\theta}}$} & $\begin{array}{l}3047 \\
3085\end{array}$ & $\begin{array}{l}2264 \\
2320\end{array}$ & & & & $\begin{array}{l}3055 \\
3085\end{array}$ & $\begin{array}{l}2285 \\
2356\end{array}$ \\
\hline $\begin{array}{l}\text { Ground } \\
\text { Excited }\end{array}$ & & $\begin{array}{l}3047 \\
3085\end{array}$ & $\begin{array}{l}2264 \\
2320\end{array}$ & & & $B_{1} g$ & $\begin{array}{l}3042 \\
3077\end{array}$ & $\begin{array}{l}2272 \\
2334\end{array}$ \\
\hline
\end{tabular}

below, together with the ground-state values calculated from the same equations. The constants $F$ and $f$ were calculated from the $A_{1}$, frequencies, while $D$ and $d$ were obtained from the $B_{1} u$ and $E_{\theta}^{+}$frequencies.

\begin{tabular}{|c|c|cccc|}
\hline & & $F$ & $f$ & $D$ & $d$ \\
\hline \multirow{2}{*}{$\mathrm{C}_{6} \mathrm{H}_{6}$} & ground & 7.6 & $5 \cdot 0$ & 0.77 & 0.60 \\
\hline & excited & 6.5 & 5.3 & 0.56 & 0.45 \\
\hline \multirow{2}{*}{$\mathrm{C}_{6} \mathrm{D}_{6}$} & ground & 7.6 & $5 \cdot 1$ & 0.82 & 0.57 \\
& excited & 6.5 & 5.3 & 0.57 & 0.46 \\
\hline
\end{tabular}

These constants cannot be regarded as more than provisional, and are given to indicate the approximate amounts by which force constants change as a result of electronic excitation. It is interesting to note the smaller changes in these in-plane force constants, as compared
with reductions of the out-of-plane constants by 50 per cent or more ${ }^{1}$. C. K. INGOLD

Sir William Ramsay and FrANCESCA M. Garforth

University College, London. June 22 .

${ }^{1}$ Nature, 157, 46 (1946).

${ }^{2}$ J. Chem. Phys., 7, 207 (1939)

J. Chem. Phys., 8, $705(1940)$

- Phys. Rev. 45, 712 (1934).

$Z$. Phys. Chem., 30, 307 (1935).

\title{
Topography of Crystal Faces
}

IN Nature of May 4, Tolansky and Wilcock ${ }^{1}$ report various features of the topography of the face of a diamond crystal, and conclude that the triangular pits often seen on the faces are due to growth, not to solution: a layer, spreading across the crystal face, does not at first cover a particula In $1: 3: 5-\mathrm{C}_{6} \mathrm{H}_{3} \mathrm{D}_{3}$ two main progressions are observed. One, in $893 \mathrm{~cm}^{-1}$, corresponds to the $A_{1 g}(\mathrm{C})$ progression, $923 \mathrm{~cm}^{-1}$ in $\mathrm{C}_{8} \mathrm{H}_{6}$ and $879 \mathrm{~cm}^{-1}$ in $\mathrm{C}_{6} \mathrm{D}_{6}$. The other, in $987 \mathrm{~cm}^{-1}$, corresponds to the but, as modifled in $\mathrm{C}_{6} \mathrm{H}_{3} \mathrm{D}_{3}$, can do so. The frequencies 893 and $987 \mathrm{~cm}^{-1}$ belong to the $A_{1}$, class of $\mathrm{C}_{8} \mathrm{H}_{3} \mathrm{D}_{3}$ vibrations, and, from $987 \mathrm{~cm}^{-1}$ belong to the $A_{1}$ class of $\mathrm{C}_{6} \mathrm{H}_{3} \mathrm{D}_{3}$ vibrations, and, from calculate, for the inactive $B^{1} u(C)$ frequencies of excited $C_{6} H_{8}$ and $C_{8} D_{8}$, the values 1001 and $948 \mathrm{~cm}^{-1}$ respectively.

the values 1001 and $948 \mathrm{~cm}^{-1}$ respectively.
Sklar, Sponer, Nordheim and Teller have determined the frequencies of the two $E_{\theta}(\mathrm{C})$ vibrations of excited $\mathrm{C}_{6} \mathrm{H}_{6}$ and $\mathrm{C}_{6} \mathrm{D}_{6}{ }^{2,3}$, and we have dealt above with the $\overrightarrow{E_{g}}$ (H-stretching) vibration. The frequencies of the $E_{\sigma}^{+}$(H-bending) vibration are identified through the observed progressions $0-0+1045+923 \nu_{1}^{\prime}$ of $\mathrm{C}_{6} \mathrm{H}_{6}$ and $0-0+775+879 \nu_{1}$
of $\mathrm{C}_{6} \mathrm{D}_{8}$. The frequencies 1045 and $775 \mathrm{~cm}^{-1}$ must belong to vibrations having $\stackrel{+}{E_{g}}$ symmetry, and we have assigned them to the $\overrightarrow{E_{g}^{+}}$(Hbending) vibration. The resulting product ratio,

$$
\underset{E_{g}}{+}\left(\mathrm{C}_{8} \mathrm{H}_{8}\right)^{\prime} / \Pi \underset{E_{g}}{+}\left(\mathrm{C}_{8} \mathrm{D}_{6}\right)^{\prime}=1 \cdot 965 \text {, }
$$

compares well with the ground-state value $1 \cdot 967$. Further confirmation arises from assignments in the $\mathrm{Ag}$ class of $1: 4-\mathrm{C}_{6} \mathrm{H}_{4} \mathrm{D}_{2}$ and tion arises from assignments

Wilson's potential function for benzene contains four in-plane force constants, which may be considered as denoting C-stretching $(F)$, constants, which may be considered as denoting C-stretching $(F)$
$\mathrm{H}$-stretching $(f)$, C-bending $(D)$, and $\mathrm{H}$-bending $(d){ }_{5,8}$. The $\mathrm{C}_{6} \mathrm{H}_{8}$ and $\mathrm{C}_{6} \mathrm{D}_{\mathrm{B}}$ frequencies which are now available for the calculation of these constants for the excited state of benzene are listed below, together with the corresponding ground-state frequencies and the percentage changes which accompany electronic excitation.

\begin{tabular}{|c|c|c|c|c|c|c|}
\hline \multirow{2}{*}{$\begin{array}{c}\text { Vibra- } \\
\text { tion }\end{array}$} & \multicolumn{3}{|c|}{$\mathrm{C}_{6} \mathrm{H}_{8}$} & \multicolumn{3}{|c|}{$\mathrm{C}_{8} \mathrm{D}_{8}$} \\
\hline & Ground & Excited & $\begin{array}{c}\% \\
\text { change }\end{array}$ & Ground & Excited & $\begin{array}{c}\% \\
\text { change }\end{array}$ \\
\hline$A_{1} g(\mathrm{C})$ & 992 & 923 & -7 & 943 & 879 & -7 \\
\hline$A_{1} g(\mathrm{H})$ & 3062 & 3130 & +2 & 2293 & 2361 & +3 \\
\hline$B_{1} u(\mathrm{C})$ & 1010 & 1001 & -1 & 963 & 948 & -2 \\
\hline$B_{1} u(\mathrm{H})$ & 3060 & 3138 & +2 & 2290 & 2337 & +2 \\
\hline$E_{g}(\mathrm{C} 1)$ & 606 & 520 & -14 & 577 & 499 & -14 \\
\hline$E_{g}^{+}(\mathrm{C} 2)$ & 1596 & 1476 & -8 & 1551 & 1408 & -9 \\
\hline$\underset{E_{\boldsymbol{q}}}{+}(\mathrm{H} 1)$ & 3047 & 3085 & +1 & 2265 & 2320 & +2 \\
\hline$\underset{E_{g}}{+}(\mathrm{H} 2)$ & 1178 & 1045 & -11 & 867 & 775 & -11 \\
\hline
\end{tabular}

Some force constants (in $10^{5}$ dynes $/ \mathrm{cm}$.), calculated from these frequencies using Kohlrausch's form of Wilson's equations, are listed

region but grows all round it, afterwards closing in on it from three
directions to form a triangular pit. We wish to report that in directions to form a triangular pit. We wish to report that, in observing certain crystais growing from solution, we have often seen this sort of thing actually happening - not of course on diamond, but on crystals of water-soluble substances, notably potassium dihydrogen phosphate. The layers we have seen, since they are easily visible under the microscope, are much thicker than those seen by Tolansky and Wilcock on diamond. Two further points are worth mentioning. One is that these pits are often irregular in shape ; this is natural enough when the advancing edges of the layers are irregular, as is the case more often than not when growth is rapid. Irregular pits found on finished crystals may therefore be due to growth, no less than regular ones. The second point is that the pits often become
completely flled in, there being afterwards no visible trace of their

With regard to the stepped pyramids seen by Tolansky and Wilcock on diamond, we have seen similar features on a number of crystals on diamond, we have seen similar features on a number of crystals, again on a much larger scale. Two photographs showing examples of
this are shown in a recently published book by one of us $^{2}$. Layers of this are shown in a recently published book by one of $\mathrm{us}^{2}$. Layers of octagonal shape have been seen on crystals of sodium chloride ; hexagonal layers are sometimes seen on cadmium iodide, but the shape is more of ten nearly circular. On octahedral faces of lead nitrate crystals, the layers are roughly triangular, but tend to have rounded or irregular edges. The thickness of the layers varies greatly with the conditions of growth, and is profoundly affected by the presence of certain impurities. Usually layers spread from a single point, roughly in the centre of a crystal face : but we have occasionally seen more than one system of layers on the same face, each spreading from a different point. On most of the crystals we have observed, the layers are much thinner near the centre than towards the edge of a face thin layers, spreading more rapidly than thicker ones, can sometimes be seen overtaking lower layers, thus adding to their thickness. It seems likely that a process of this kind-the building of thick layers from thinner ones-goes on, right down to the ionic scale. A system of submicroscopic layers would constitute a low pyramid of vicinal faces, and the curvature of vicinal faces mentioned by Tolansky and Wilcock may well be connected with a gradual change of layer thickness from the centre of a face towards the edges.

A more detailed account of this work will be published elsewhere.

C. W. BUNN

Research Department,
I.C.I. Limited, Alkali Divisio

Northwich, Cheshire.

'Tolansky, S., and Wilcock, W. I., Nature, 157, 583 (1946).

'Bunn, C. W., “Chemical Crystallography” (Clarendon Press, 1945).

\section{A Convenient and Efficient Fractionating Column and its Use in the Separation of the Heavy Isotopes of Hydrogen and Oxygen}

THE performance of a fractionating column recently constructed and used in this Department prompts us to place on record its chief characteristics. The column is packed with miniature (1/16 in.) 2 shaped 'rings' of phosphor-bronze gauze (100 mesh) and is enclosed in a vacuum jacket containing multiple, concentric aluminium reflectors. The length of the packed section is $12 \mathrm{ft}$. and its internal diameter is 